REGARDS

SUR L'ECONOMIE ALLEMAND

BULLETIN ECONOMIQUE DU CIRAC
Regards sur l'économie allemande

Bulletin économique du CIRAC

$88 \mid 2008$

Varia

\title{
Conjurer le spectre de la récession
}

\section{René Lasserre}

\section{OpenEdition}

\section{Journals}

Édition électronique

URL : http://journals.openedition.org/rea/2743

DOI : $10.4000 /$ rea. 2743

ISBN : 978-2-8218-0872-0

ISSN : 1965-0787

Éditeur

CIRAC

Édition imprimée

Date de publication : 1 octobre 2008

Pagination : 1-2

ISSN : 1156-8992

Référence électronique

René Lasserre, "Conjurer le spectre de la récession », Regards sur l'économie allemande [En ligne], 88 | octobre 2008, mis en ligne le 12 janvier 2009, consulté le 22 septembre 2020. URL : http:// journals.openedition.org/rea/2743 ; DOI : https://doi.org/10.4000/rea.2743 


\section{Conjurer \\ le spectre de la récession}

L'économie allemande, qui depuis deux ans affichait une croissance et une confiance qui semblaient à toute épreuve, se retrouve maintenant confrontée de plein fouet à la crise. Le ralentissement conjoncturel qui s'était amorcé au printemps sous l'effet de la montée des prix du pétrole, de l'euro fort et du tassement de la demande mondiale s'est depuis lors visiblement amplifié. Et même si la croissance de l'Allemagne semble pour l'instant devoir mieux résister que celle de ses voisins européens sur l'année 2008, les perspectives se sont considérablement assombries pour les prochains mois comme en témoigne la chute spectaculaire et concordante des indices de confiance au cours de l'été.

Avec le déferlement de la crise bancaire en Europe, où l'Allemagne s'est retrouvée en première ligne pour parer à l'écroulement de son système bancaire et sauvegarder la confiance des déposants, l'inquiétude atteint maintenant son paroxysme. Alors que jusqu'alors avait prévalu en Allemagne la ferme conviction que les soubresauts de la "bulle financière " ne parviendraient pas à ébranler la solidité de l'économie réelle, on redoute désormais que, par son ampleur, la crise financière ne plonge le pays et l'ensemble du marché européen dans la récession. La raréfaction prévisible du crédit fait peser de lourdes incertitudes sur la consommation des ménages, sur le marché immobilier et l'investissement des entreprises, risquant de conduire à un recul durable de l'activité et de l'emploi. Les réductions de capacités qui s'accentuent dans l'industrie automobile ou dans l'activité de service aux entreprises en sont un premier et inquiétant signal.

Au-delà de la restauration immédiate de la confiance des agents économiques et des épargnants dans le système bancaire, laquelle relève d'abord de la responsabilité des gouvernements nationaux, il importe également d'enrayer à court terme cette spirale récessive par une action conjuguée au plan européen. Et ce afin d'assurer la liquidité des banques et de faciliter l'accès au crédit, au besoin par une baisse des taux. Tout aussi importantes sont la remise en ordre et la transparence des marchés financiers, même si celles-ci relèvent de régulations plus larges et sans doute plus longues à mettre en place.

Mais on voit bien, à la lumière de l'expérience de ces derniers jours, toutes les difficultés d'une action européenne concertée qui se heurte à des différences patentes d'approche et de doctrine dans lesquelles le contraste franco-allemand est, une fois de plus, flagrant. Différences dans les intérêts et les finalités : entre d'un côté une volonté française de mettre en avant, à la faveur de la crise, l'objectif d'une politique de croissance fondée sur le soutien à la demande, le desserrement de la contrainte monétaire et l'assouplissement des disciplines du pacte de stabilité ; et de l'autre, une approche d'inspiration allemande qui tient à préserver un équilibre de stabilité monétaire et de rigueur financière qui concourt à la compétitivité globale de l'espace européen. Différences aussi dans les conceptions et les modes d'action institutionnels : entre 
d'une part une approche française d'inspiration volontariste qui privilégie des solutions européennes globales, à l'instar de la proposition d'une version européenne du plan Paulson, et une approche allemande inspirée de subsidiarité et qui s'attache à définir les niveaux pertinents de responsabilité et d'action. Au niveau national, il revient à chacun de " gérer correctement sa maison "; au niveau européen ne s'impose que l'action commune sur des objectifs clairement définis et réellement partagés.

Il importe de surmonter ces différences pour gérer efficacement la crise bancaire et mettre en œuvre les solutions appropriées pour que l'approvisionnement optimal des économies européennes en crédit soit restauré au plus vite. Ce n'est qu'à cette condition que la menace d'une récession grave et durable en Europe pourra être écartée. Sur la base de l'acquis inestimable que constituent l'existence de la Banque Centrale Européenne et de la monnaie unique, cela constitue un objectif réaliste et accessible.

L'opération n'est certes pas gagnée d'avance. Mais, en tout état de cause, c'est une épreuve de vérité pour l'Europe.

René Lasserre, le 8 octobre 2008 